\title{
Desafios na compreensão de textos em espanhol como língua estrangeira: saberes e reflexões
}

\author{
Retos en la comprensión de textos en español como \\ lengua extranjera: saberes y reflexiones
}

\author{
Challenges in understanding of texts in Spanish \\ as a foreign language: knowledges and reflexions
}

Antônio Carlos Silva Júnior*

\begin{abstract}
RESUMO: $O$ ato de ler constitui um processamento da linguagem que ocorre de forma complexa e de diferentes modos a depender do leitor. Nessa perspectiva, o presente estudo tem como objetivo principal analisar a compreensão de textos em espanhol como língua estrangeira (ELE) com alunos de quatro escolas da rede pública na cidade de Aracaju, Sergipe. Os pressupostos teóricos do trabalho estão baseados em Kleiman (1998), Solé (1998), Koch (2003), Alliende e Condemarín (2005), Marcuschi (2008), entre outros. Para tanto, buscou-se, através de cinco oficinas de leitura com diferentes gêneros discursivos: avaliar a compreensão literal e inferencial; verificar a reorganização, a avaliação e a leitura crítica; e comparar, entre os gêneros, as dificuldades encontradas na compreensão. A taxonomia de Barret foi utilizada como referência para a análise das atividades leitoras, o que possibilitou a descrição dos fatores que podem interferir nesse processo facilitando ou dificultando o trabalho do leitor que apresenta dificuldades na compreensão. Com os dados obtidos, foi possível verificar que a temática tratada no texto, o gênero, a linguagem empregada, e o conhecimento prévio influenciam no processo leitor. No entanto, tais aspectos provocaram alguns questionamentos acerca da limitada compreensão de alguns estudantes que, por estarem no Ensino Médio, deveriam demonstrar mais habilidade na compreensão de temáticas e gêneros que estão além das suas vivências. Visto isso, reconheceu-se a importância de um trabalho ampliado e contextualizado de leitura no contexto escolar, pois isso contribuirá para que o leitor possa trafegar em diferentes contextos comunicativos de modo mais eficaz.
\end{abstract}

PALAVRAS-CHAVE: Compreensão textual. Dificuldades. Espanhol como língua estrangeira. Leitura.

\footnotetext{
*Doutorando em Língua e Cultura pela Universidade Federal da Bahia (PPGLinC/UFBA). Mestre em Letras (Estudos Linguísticos) pela Universidade Federal de Sergipe (UFS). Professor de Espanhol na rede pública do estado de Sergipe. E-mail: carlosjunior.hispanico@gmail.com.
} 
RESUMEN: El acto de leer constituye un procesamiento del lenguaje que ocurre de forma compleja y de distintos modos a depender del lector. En esa perspectiva, el presente estudio tiene como objetivo principal analizar la comprensión de textos en español como lengua extranjera (ELE) con alumnos de cuatro escuelas de la red pública en la ciudad de Aracaju, Sergipe. Los presupuestos teóricos del trabajo están basados en Kleiman (1998), Solé (1998), Koch (2003), Alliende e Condemarín (2005), Marcuschi (2008), entre otros. Para tanto, se buscó, a través de cinco talleres de lectura con diferentes géneros discursivos: evaluar la comprensión literal e inferencial; verificar la reorganización, la evaluación y la lectura crítica; y comparar, entre los géneros, las dificultades encontradas en la comprensión. La taxonomía de Barret fue utilizada como referencia para el análisis de las actividades lectoras, lo que posibilitó la descripción de los factores que pueden interferir en ese proceso facilitando o dificultando el trabajo del lector que presenta dificultades en la comprensión. Con los datos obtenidos, fue posible verificar que la temática tratada en el texto, el género, el lenguaje empleado, y el conocimiento previo influyen en el proceso lector. Sin embargo, tales aspectos provocaron algunos cuestionamientos a cerca de la limitada comprensión de algunos estudiantes que, por estar en la Enseñanza Secundaria, deberían demostrar más habilidad en la comprensión de temáticas y géneros que están allá de sus vivencias. Por consiguiente, se ha reconocido la importancia de un trabajo ampliado y contextualizado de lectura en el contexto escolar, pues eso contribuirá para que el lector pueda circular en distintos contextos comunicativos de modo más eficaz.

PALABRAS CLAVE: Comprensión textual. Dificultades. Español como lengua extranjera. Lectura.

ABSTRACT: The act of reading is a language processing that occurs in a complex way and in different ways depending on the reader. In this perspective, the present study has as main objective to analyze the comprehension of texts in Spanish as a foreign language (SFL) with students from four public schools in the city of Aracaju, Sergipe. The theoretical assumptions of the work are based on Kleiman (1998), Solé (1998), Koch (2003), Alliende e Condemarín (2005), Marcuschi (2008), among others. Therefore, five reading workshops with different textual genres were used to evaluate literal and inferential comprehension; Verify reorganization, evaluation and critical reading; and to compare the difficulties encountered in understanding between genders. Barret's taxonomy was used as a reference for the analysis of reading activities, which enabled the description of factors that may interfere in this process, facilitating or hindering the work of the reader who presents difficulties in comprehension. With the data obtained, it was possible to verify that the theme dealt in the text, the genre, the language used, and the previous knowledge influence the reader process. However, these aspects have raised some questions about the limited understanding of some students who, because they are in high school, should demonstrate more ability in understanding the themes and genres that are beyond their experiences. Given this, it was recognized the importance of an extended and contextualized reading work in the school context, as this will contribute to the reader being able to travel in different communicative contexts more effectively.

KEY WORDS: Reading comprehension. Difficulties. Spanish as a foreign language. Reading. 


\section{Considerações Iniciais}

$\mathrm{O}$ ato de ler constitui uma atividade complexa que não pode ser reduzida a uma mera decifração de códigos. Tal ação se produz de modo processual, que decorre desde o conhecimento prévio do leitor, a decodificação, a organização textual, até a construção de sentidos.

Vista então como processo, um caminho a ser percorrido, a leitura pressupõe em sua concepção a participação ativa de saberes que interferem diretamente na produção de significados, por isso a escolha da concepção sociocognitiva de leitura para embasar esse estudo e a importância de se refletir sobre o trabalho com diferentes gêneros discursivos, instrumentos da comunicação linguística no processo leitor.

A partir do trabalho como professor em sala de aula e ao perceber que muitos alunos não tinham um bom rendimento por apresentar um baixo desempenho em questões de compreensão leitora, surgiu o interesse pela identificação de tais dificuldades e dos problemas encontrados por leitores na compreensão da linguagem escrita em espanhol como língua estrangeira $(E / L E)$. Nessa perspectiva, o presente trabalho é um recorte de uma pesquisa ${ }^{1}$ realizada durante o mestrado em Letras (Estudos Linguísticos) cursado na Universidade Federal de Sergipe e versa sobre as dificuldades na compreensão de textos em espanhol como língua estrangeira.

Para a concretização dos propósitos deste estudo, apresentam-se as três perguntas norteadoras que motivaram a busca de respostas através da pesquisa:

Como se dá a compreensão literal e inferencial de textos em espanhol como língua estrangeira?

De que maneira alunos com dificuldades de leitura em espanhol reorganizam, avaliam e leem criticamente?

\footnotetext{
${ }^{1}$ Os estudos citados resultaram na dissertação escrita pelo mesmo autor, intitulada Dificuldades na compreensão de textos em espanhol como língua estrangeira: caminhos e desafios da leitura, e defendida em julho de 2015. 
Em que medida, os gêneros discursivos e as temáticas apresentadas influenciam na compreensão de textos em língua espanhola?

No processo investigativo, tais problemáticas foram destrinchadas e constituíram as categorias de análise da pesquisa. Com isso, conjecturaram-se algumas possíveis hipóteses sobre os fatores que atuam facilitando ou dificultando a compreensão literal, como o léxico, a compreensão inferencial, a reorganização, a avaliação e a leitura crítica, como aspectos relacionados ao conhecimento prévio, de mundo e de organização textual, e à semântica (aspectos linguísticos e de significado).

Sendo assim, o objetivo principal da pesquisa aqui descrita foi analisar a compreensão de textos em espanhol como língua estrangeira ( $E / L E)$ com alunos que possuem dificuldades para ler textos em língua espanhola.

Para que tal objetivo fosse alcançado, alguns objetivos específicos foram traçados. São eles:

Avaliar a compreensão literal e inferencial;

Verificar a reorganização, a avaliação e a leitura crítica; e

Comparar, entre os gêneros, as dificuldades encontradas na compreensão.

A preocupação em pensar como a compreensão leitora em espanhol pode ser aprimorada e efetivada vem da percepção de que ler constitui um processamento de linguagem que ocorre de forma complexa e de diferentes formas a depender do leitor. Para alguns, com maior eficácia, fluência e agilidade, para outros, com certa dificuldade, contato com obstáculos e lentidão.

\section{A Leitura Como Prática de Uso e Objeto Relevante de Pesquisa}

Ao propor uma reflexão sobre as dificuldades na compreensão de textos em espanhol como língua estrangeira, a presente pesquisa é condizente com a necessidade subscrita por Moita Lopes (2006, p. 23) de "teorizações que 
dialoguem com o mundo contemporâneo, com as práticas sociais que as pessoas vivem, como também desenhos de pesquisa que considerem diretamente os interesses daqueles que trabalham, agem, etc."

Inserido no campo aplicado de estudos da linguagem, na área da Linguística Aplicada (LA), este trabalho ancora-se na compreensão de que o objeto desse campo de estudos, tal qual propõe Moita Lopes (2006), são problemas linguísticos socialmente relevantes. Tais problemas são entendidos nesta investigação como aqueles que acarretam dificuldades na vida social das pessoas a partir da linguagem.

Para Rojo (2007), a atividade do linguista aplicado tem convergido com o interesse em entender, explicar ou solucionar problemas, objetivando a criação ou o aprimoramento de soluções para tais problemas, tomados em sua contextualização, em sua relevância social, o que confere às soluções condição de conhecimento útil a participantes sociais efetivos.

Em se tratando de dificuldades na compreensão de textos em espanhol como língua estrangeira, tais obstáculos implicam na formação de usuários da língua em foco, e até mesmo da materna, que necessitam interagir na sociedade, mediados pela modalidade escrita, em diferentes esferas da atividade humana, seja escolar ou não.

A Linguística Aplicada, por sua natureza transdisciplinar, busca contribuir para a compreensão de fenômenos linguísticos situados na sociedade. Nessa perspectiva, a escola tem sido o campo mais frequente das pesquisas em Linguística Aplicada, uma vez que os processos de ensino e aprendizagem de língua materna ou de línguas estrangeiras envolvem fundamentalmente a língua em uso através de mostras concretas de múltiplos gêneros autênticos que circulam em diferentes esferas sociais.

Kleiman (1998, p. 70) comenta que o foco de interesse da LA não é a linguagem em si, mas o conhecimento das práticas de uso e de aprendizagem da língua em instituições, porque seu conhecimento pode ajudar a entender os fatores que condicionam as práticas institucionais (sociais). 
Somos leitores em tempo integral, mas não lemos do mesmo jeito os diferentes textos que se apresentam. É papel da escola fornecer aos estudantes, através da leitura, os instrumentos necessários para que eles consigam buscar, analisar, selecionar, relacionar, organizar as informações complexas do mundo contemporâneo e exercer a cidadania.

Sendo assim, com todas as transformações pelas quais a sociedade vivencia, as oportunidades de contato com diferentes tipos de linguagens já são comuns, como a difusão de Línguas Estrangeiras, seja pela escola, mídia, entre outros, resultado da globalização. Nesse sentido, ler em língua estrangeira passou também a ser uma realidade no mundo atual e, nas escolas, isso se comprova pela sua inserção objetivando, principalmente, o domínio da habilidade leitora.

Apesar de algumas particularidades, o desenvolvimento da construção do ensino-aprendizagem da leitura, tanto em Língua Materna (LM) como em Língua Estrangeira (LE), apresenta semelhanças em seu discurso pedagógico. Nos dois contextos, a concretização da atividade advém do processo sócio interacional entre os sujeitos, isto é, da construção social (Moita Lopes, 1996).

Nessa perspectiva, o aprendiz transfere sua percepção sobre o processo leitor construída ao longo do processo educativo formal da LM para a LE. Normalmente, essa representação reflete um modelo de leitura que revela uma série de procedimentos que são executados com a finalidade de alcançar a compreensão.

As Orientações Curriculares para o Ensino Médio- OCEM (BRASIL, 2006) fazem uma reflexão acerca da leitura na sala de aula e entendem que é necessário o conhecimento integrador e não dividido, a não redução do conhecimento segundo os próprios interesses ou circunstâncias. $O$ documento também defende a formação de leitores independentes e críticos, para que possam refletir sobre sua sociedade e ampliem sua visão de mundo.

Diante disso, entende-se a importância de o mediador, nesse caso o professor, tornar a prática de leitura algo prazeroso e não mecânico, e ao 
mesmo tempo com um propósito educacional, pois precisa criar o gosto pela leitura em seus alunos por meio de atividades significativas. Para tanto, conhecer o processo leitor de forma mais aprofundada e reconhecer os fatores que o facilitam e o dificultam contribuirão para que sua prática como docente seja mais consciente, contextualizada e, consequentemente, eficaz.

\section{A Leitura em Prol da Compreensão das Múltiplas Linguagens}

Segundo Solé (1998, p. 44) "ler é compreender e compreender é, sobretudo, um processo de construção de significados sobre o texto que pretendemos compreender". Para tanto, a compreensão de um texto envolve ativamente a participação do leitor que faz uso de recursos para sua efetivação.

De acordo com Alliende e Condemarín (2005, p. 111), a compreensão dos textos escritos é apontada como a "reconstrução, por parte do leitor, do sentido dado pelo autor a um determinado texto", ou seja, "o emissor codifica uma mensagem que o receptor, por manejar o mesmo código, pode decodificar". Para os autores, a complexidade da atividade de leitura é determinada por fatores que podem ser derivados do emissor, do texto ou do leitor, que facilitam ou dificultam o processamento e que são constituídos por aspectos que, se dominados, contribuirão no processo leitor.

Para tratar de leitura, é imprescindível aprofundar acerca da matériaprima utilizada no desenvolvimento desse processo: o texto. Com o intuito de representar o mundo, exprimir seu pensamento, comunicar-se e influenciar os outros, o ser humano faz uso de textos. Tanto a linguagem verbal quanto a linguagem não verbal expressam sentidos e, para isso, signos são utilizados e combinados entre si, de acordo com certas leis, obedecendo a mecanismos de organização.

Bakhtin (1997, p. 329) considera o texto sob diferentes prismas e problemas, um dos quais constitui uma primeira noção ampliada do conceito ao afirmar que "o texto representa uma realidade imediata (do pensamento e da 
emoção), a única capaz de gerar essas disciplinas e esse pensamento. Onde não há textos, também não há objeto de estudo e de pensamento".

A partir dessa afirmação, percebe-se o importante lugar que o texto ocupa na produção e expressão do pensamento, assim como a necessidade que há de estudos que contemplem esse tema em toda sua complexa dimensão.

Quando se fala em texto, normalmente se pensa na linguagem verbal, ou seja, naquela capacidade humana ligada ao pensamento que se concretiza numa determinada língua e se manifesta por palavras. Entretanto, além dessa, há outras formas de linguagem, formas estas que são dinâmicas e, ao mesmo tempo, autênticas, que atuam em diferentes contextos de comunicação, que são veiculadas de múltiplas formas e que perpassam umas nas outras somando na construção de sentidos.

Essa forma linguística com aspectos sociais próprios, finalidades comunicativas e especificidades das situações de interação é chamada de gênero textual. Segundo Marcuschi (2008, p. 154),

[...] é impossível não se comunicar verbalmente por algum gênero, assim como é impossível não se comunicar verbalmente por algum texto. Isso porque toda a manifestação verbal se dá sempre por meio de textos realizados em algum gênero. Daí a centralidade da noção de gênero textua/ no trato sociointerativo da produção linguística.

Bakhtin (1997, p. 279) denominou tais formas linguísticas de gêneros discursivos e os definiu como "tipos relativamente estáveis de enunciados". Os gêneros utilizados nas interações verbais pelos interlocutores sociais são tão diversos e heterogêneos quanto à diversidade de esferas de circulação social nas interações verbais e na diversidade da atividade humana.

O autor também afirma que, nas diversas esferas de circulação, "a utilização da língua se efetua em forma de enunciados" pela heterogeneidade de gêneros que os constitui e, de acordo com as condições e finalidades de cada uma dessas esferas, podemos encontrar uma diversidade de gêneros discursivos que se modificam e se ampliam a cada novo contexto social e 
Desafios na compreensão de textos em espanhol como língua estrangeira:

saberes e reflexões

histórico de circulação. Para um melhor entendimento da questão, Marcuschi (2008, p. 155) os caracteriza e os define afirmando que

[...] refere os textos materializados em situações comunicativas recorrentes. [...] são os textos que encontramos em nossa vida diária e que apresentam padrões sociocomunicativos característicos definidos por composições funcionais, objetivos enunciativos e estilos concretamente realizados na integração de forças históricas, sociais, institucionais e técnicas.

Nesse sentido, os gêneros discursivos operam em um envolvimento social, real e associado às atividades humanas. Sua composição assume um caráter dinâmico, mas que ao mesmo tempo possui uma identidade que faz com que os enunciadores escolham entre um ou outro a depender da situação concreta de comunicação da qual estejam participando. Alguns exemplos de gêneros que podem ser enumerados e que foram indicados também por Marcuschi (2008, p. 155) seriam:

[...] telefonema, sermão, carta comercial, carta pessoal, romance, bilhete, reportagem jornalística, aula expositiva, reunião de condomínio, notícia jornalística, horóscopo, receita culinária, bula de remédio, lista de compras, cardápio de restaurante, instruções de uso, outdoor, inquérito policial, resenha, edital de concurso, piada, conversação espontânea, conferência, carta eletrônica, bate-papo por computador, aulas virtuais e assim por diante.

Com isso, conclui-se que o papel dos gêneros discursivos tem sido reconhecido como fundamental na interação sociocomunicativa e, em vista disso, eles passaram a nortear o ensino de línguas, especialmente o trabalho com análise, interpretação e produção de textos. Essa abordagem favorece o desenvolvimento da competência linguística e discursiva e, consequentemente, amplia a participação social do indivíduo. Por isso, os Parâmetros Curriculares Nacionais preconizam o ensino da leitura e produção de textos a partir de gêneros discursivos. (BRASIL, 2000).

A integração de várias linguagens envolvendo palavras, imagens, sons, entre outras, tornou-se a principal característica das produções textuais 
vinculadas na comunicação, principalmente nas mídias digitais com o aumento no uso de ambientes virtuais e redes sociais. As constantes modificações nas formas de interação e comunicação entre os sujeitos e o desenvolvimento tecnológico têm gerado o surgimento de novas e múltiplas linguagens que produzem diferentes formas textuais heterogêneas na sociedade contemporânea.

Essas mudanças significativas com relação à linguagem em uso trazem à tona um novo tipo de texto, que se mostra bastante recorrente nas práticas sociais atualmente: o texto multimodal. Segundo Dionísio (2011, p. 162),

[...] a Multimodalidade refere-se às mais distintas formas e modos de representação utilizados na construção de uma dada mensagem, tais como: palavras, imagens cores, formatos, marcas/ traços tipográficos, disposição da grafia, gestos, padrões de entonação etc.

Nesse sentido, a multimodalidade engloba a escrita, a fala e a imagem. Mayer (2010 apud PAES DE BARROS, 2009, p. 165) define como multimedia "o material que associa palavras ao material pictográfico, sendo que palavras designam os textos verbais (tanto em impressos como em textos orais) e o material pictográfico inclui gráficos, ilustrações, fotografias, mapas". Assim, o termo multimedia "abrange não somente os textos digitais como também os textos impressos".

Tudo isso rompe com a perspectiva monomodal, que dava prioridade ao código verbal (palavras) na construção textual. A partir dos anos 90, os chamados "textos não canônicos" passaram a fazer parte do escopo de estudos da Linguística Textual, subdisciplina da Linguística que surge em meados dos anos 60 do século XX, e nessa categoria estão (também) inseridos os textos multimodais. É inegável que os sistemas de textos cada vez mais complexos, característicos da comunicação e interação sociais não só convergem para novos formatos de texto, mas também exigem novos tipos de análise.

Segundo Koch (2003, p. 3): 
Desafios na compreensão de textos em espanhol como língua estrangeira:

saberes e reflexões

Determinados aspectos de nossa realidade social só são criados por meio da representação dessa realidade e só assim adquirem validade e relevância social, de tal modo que os textos não apenas tornam o conhecimento visível, mas, na realidade, sociocognitivamente existente. A revolução e evolução do conhecimento necessita e exige, permanentemente, formas de representação notoriamente novas e eficientes.

Entende-se, então, que a crescente integração das várias formas de linguagem passa a ser emergente na produção textual que representa a complexa sociedade atual. Nesse sentido, os textos multimodais são aqueles representados por "um conjunto de múltiplas formas de representação ou códigos semióticos que, através de meios próprios e independentes, realizam sistemas de significados." (SELVATICI, 2007, p. 1).

Percebe-se, então, que as linguagens verbal e não verbal se integram de forma coerente e coesa para a formação de um texto mais "completo" e, nesse sentido, a multimodalidade precisa ser analisada sob a perspectiva de uso de ambas as formas de linguagem.

\begin{abstract}
No caso dos textos multimodais, por exemplo, tanto os elementos verbais como os não verbais devem ser considerados como parte de um todo que é o texto. A análise empreendida deve considerar esse todo e não ser segmentada na análise de pequenos textos, verbais de um lado e não verbais de outro. Portanto, os elementos não verbais são fundamentais e inevitavelmente constitutivos dos textos multimodais e incorporá-los na análise se faz necessário para explicar e compreender a forma como ocorre, também nesses textos, 0 processo de compreensão. (PINHEIRO, 2012, p. 7).
\end{abstract}

Dessa forma, conclui-se que o texto multimodal, tão característico da sociedade atual, insere-se nos interesses de estudo da Linguística Textual por se tratar de uma representação (da realidade) notoriamente eficiente.

Sendo assim, recorre-se mais uma vez a Dionísio (2011, p. 138), que diz que, "na atualidade, uma pessoa letrada deve ser alguém capaz de atribuir sentidos às mensagens oriundas de múltiplas fontes de linguagem". Partindo dessa perspectiva, na sociedade contemporânea, a competência leitora é algo de fundamental importância e como tal deve abranger suas múltiplas modalidades. 
Desafios na compreensão de textos em espanhol como língua estrangeira: saberes e reflexões 


\section{Contexto e Metodologia da Pesquisa}

A ciência tem como objetivo fundamental conferir a veracidade dos fatos. Para isso, é preciso utilizar o método científico, o qual define as diretrizes e orientações de como desenvolver o trabalho de pesquisa, as técnicas que devem ser empregadas, a sequência adequada de atividades, etc., com 0 intuito de conferir um grau de confiabilidade aos resultados obtidos.

Nesse sentido, os procedimentos metodológicos constituem uma importante parte da pesquisa, uma vez que nortearão o trabalho do pesquisador para atingir seus objetivos de forma planejada e fundamentada.

$O$ presente estudo insere-se tanto na abordagem qualitativa como na quantitativa, a chamada pesquisa quali-quanti. A metodologia construída agrupou aspectos de ambas perspectivas com o intuito de fazer uso de mais de um instrumento de pesquisa na mensuração das principais variáveis do estudo.

Para Godoy (1995, p. 58), através da abordagem qualitativa tem-se "[...] a obtenção de dados descritivos sobre pessoas, lugares e processos interativos pelo contato direto do pesquisador com a situação estudada, para compreender os fenômenos segundo a perspectiva dos sujeitos, ou seja, dos participantes da situação em estudo". Nesse sentido, visto que a linguagem só é produzida ou interpretada em um dado contexto social e que foram realizadas oficinas para investigar a atuação compreensiva dos sujeitos frente a textos em espanhol como língua estrangeira, essa investigação demanda uma análise sob a ótica qualitativa de pesquisa.

No entanto, ao fazer uso de dados numéricos, como a quantidade de erros e acertos nas atividades, para explicar a ocorrência de um determinado fenômeno, essa pesquisa também caracteriza-se dentro da abordagem quantitativa. Os métodos quantitativos de pesquisa se baseiam no paradigma positivista, onde a racionalidade reina de forma absoluta. Para tanto, são utilizados nesse tipo de pesquisa, métodos quantitativos, ou seja, ancorados em 
números que tentam, tão somente, representar uma realidade temporal observada.

Segundo seu objetivo mais geral, já que a pesquisa aqui caracterizada pretende verificar os fatores que dificultam a compreensão de textos em espanhol como língua estrangeira, pode ser classificada como explicativa, pois tem "como propósito identificar fatores que determinam ou contribuem para a ocorrência de fenômenos" (GIL, 2010, p. 28).

Adotou-se como método de coleta de dados a observação participante, na qual o próprio investigador é o instrumento principal de observação. Assim, a participação tem por objetivo recolher dados (sobre ações, opiniões ou perspectivas) aos quais um observador exterior não teria acesso. A observação participante é uma técnica de investigação qualitativa adequada ao investigador que pretende compreender, num meio social, um fenómeno que the é exterior e que Ihe vai permitir integrar-se nas atividades/vivências das pessoas que nele vivem.

Como campo de estudo para realização da presente pesquisa, foram escolhidas quatro escolas da rede estadual situadas na cidade de Aracaju, capital do estado de Sergipe. Tal escolha se deu a partir do contato inicial com os professores de espanhol das instituições focando na seguinte especificidade: presença de alunos do Ensino Médio com baixo rendimento devido a dificuldades na compreensão de textos em espanhol como língua estrangeira. Por questões éticas, os nomes das escolas participantes serão mantidos em sigilo e, por isso, chamadas de Escola I, Escola II, Escola III e Escola IV.

No que se refere aos participantes da pesquisa, o estudo foi realizado com um total de 30 (trinta) estudantes e, para fins didáticos, abaixo há um quadro com a distribuição dos principais dados do grupo constituído em cada escola. 
Desafios na compreensão de textos em espanhol como língua estrangeira: saberes e reflexões

Quadro 1 - Principais dados do corpus da pesquisa

\begin{tabular}{|l|l|l|l|l|}
\hline \multirow{3}{*}{ Escolas } & \multicolumn{2}{|l|}{ Ano } & \multirow{2}{*}{ Quantidade de alunos } \\
\cline { 2 - 5 } & $\mathbf{1}^{\mathbf{0}}$ & $\mathbf{2}^{\mathbf{0}}$ & $\mathbf{3}^{\mathbf{0}}$ & \\
\hline Escola I & - & 05 & - & 05 \\
\hline Escola II & 11 & 14 & - & 14 \\
\hline Escola III & 02 & 03 & - & 03 \\
\hline Escola IV & - & 08 & 05 & 08 \\
\hline Total & 13 & 30 & 05 & 30 \\
\hline
\end{tabular}

Fonte: Autor

Pelo quadro acima, nota-se uma disparidade no número de alunos por escola, tal aspecto justifica-se pela informação passada pelos professores contatados e pela particularidade de cada escola com relação à presença de alunos com baixo rendimento e dificuldades na compreensão de textos em espanhol, como fora explicitado anteriormente.

Por questões éticas, os nomes dos estudantes participantes serão mantidos em sigilo e, por isso, durante as análises e caso se faça necessário citar alguns deles ou fazer recortes de suas respostas, serão chamados de Leitor 01, Leitor 02 e assim sucessivamente, seguindo a numeração a partir de cada escola.

Instrumento de coleta de dados

A prática de leitura por meio de materiais autênticos, frente aos textos artificialmente fabricados tão presentes em livros didáticos antigos, justifica-se por propiciar uma aproximação das possibilidades de leitura existentes fora da sala de aula em contextos reais de uso. Entende-se sobre textos autênticos todo material escrito ou oral veiculado socialmente para satisfazer uma finalidade. Sobre esse aspecto, Fontana (2003, p. 10) afirma que 
Desafios na compreensão de textos em espanhol como língua estrangeira:

saberes e reflexões

[...] a utilização desse tipo de material na educação em LE não se propõe a ser uma nova metodologia, mas uma possibilidade de realizar a mediação entre recurso linguístico e uso da língua, num continuum não-dicotomizado e não-linear, a partir de textos de qualquer natureza $[. .$.$] , criados para satisfazer um propósito na vida$ social da comunidade linguística que os produz.

Cada oficina contemplou um gênero de texto específico objetivando analisar a compreensão de textos em espanhol a partir de experiências de leitura com diferentes gêneros que circulam na sociedade. Com um total de cinco oficinas e, por consequência, cinco gêneros, optou-se por trabalhar com quadrinhos, contos, anúncios publicitários, poesias e notícias. Justificam-se tais escolhas devido ao fato de serem gêneros possivelmente já conhecidos na língua materna e/ou, também, em espanhol, e para propiciar um trabalho que concebesse uma heterogeneidade textual, incluindo textos uni e multimodais.

As atividades de cada uma das cinco oficinas foram elaboradas tomando como referência cinco pontos da taxonomia de Barret (1968 apud ALLIENDE; CONDOMARÍN, 2005)², que inclui as dimensões cognitivas e afetivas da compreensão de leitura. São elas: Compreensão literal; Reorganização; Compreensão Inferencial; Avaliação e; Leitura crítica.

Outro aspecto a ser levado em consideração na elaboração das atividades é a estruturação das perguntas que constituíram itens de resposta livre e itens de resposta orientada, estes apresentados em maior escala em versões de itens de múltipla escolha, segundo as orientações formuladas pelo Instituto Nacional de Estudos e Pesquisas Educacionais Anísio Teixeira (INEP).

De acordo com o Guia de Elaboração e Revisão de Itens (INEP, 2010), o termo item pode ser considerado sinônimo de questão, unidade básica de um instrumento de coleta de dados, que pode ser uma prova, um questionário etc.

\footnotetext{
${ }^{2}$ A compreensão em leitura, na forma em que é tratada na taxonomia, é dividida em cinco grandes categorias ou níveis de habilidade: (a) compreensão literal; (b) reorganização; (c) compreensão inferencial; (d) leitura crítica e (e) avaliação. Dentro de cada uma dessas categorias, Barret fornece exemplos de tarefas específicas, no formato de propósitos de leitura, os quais o professor pode utilizar em sua prática em sala de aula. As categorias foram ordenadas como um guia progressivo de compreensão textual, de modo a se deslocarem das mais fáceis para as mais difíceis em termos das solicitações demandadas em cada uma delas. 
Desafios na compreensão de textos em espanhol como língua estrangeira: saberes e reflexões

Para tanto, no intuito de contemplar itens que possibilitassem a aplicação da taxonomia de Barret, as atividades criadas foram construídas através da composição de questionamentos seguindo a tipologia de perguntas de compreensão ${ }^{3}$ apresentadas por Mascuschi (2008) para analisar os exercícios de compreensão nos livros didáticos de língua portuguesa.

A fim de desenvolver um meio compreensível e manejável de ensinar a compreensão, Barret (1968 apud ALLIENDE; CONDOMARÍN, 2005) lança sua Taxonomia das Dimensões Afetivas e Cognitivas da Compreensão Leitora, utilizada nesta pesquisa como categorias de análise das atividades de compreensão aplicadas nas oficinas de leitura.

A taxonomia de Barret (apud ALLIENDE; CONDOMARÍN, 2005) originalmente aplicada a textos narrativos, foi aqui adaptada para seu uso também com textos não narrativos. Com o desenvolvimento de instrumentos de análise alternativos, baseado em tal taxonomia, procurou-se avaliar a compreensão de textos em espanhol como língua estrangeira. Através desses instrumentos, buscou-se verificar a compreensão do texto em maior profundidade e sua efetivação, ou não, nas diferentes categorias da taxonomia. Nas oficinas aplicadas, buscaram-se contemplar diferentes níveis de compreensão, escolhidos segundo cada uma das propostas.

\section{Análise Dos Dados}

Este trabalho se propôs a desenvolver uma análise da compreensão de textos em espanhol como língua estrangeira a partir da aplicação de oficinas de leitura, tendo como informantes trinta aprendizes sergipanos de quatro escolas públicas estaduais.

Nessa pesquisa, os dados coletados se restringem a situações envolvidas dentro de conjunturas específicas em que o contexto escolar, a formação inicial

\footnotetext{
${ }^{3}$ Em seu livro Produção de texto, análise de gêneros e compreensão, Marcuschi (2008) apresenta uma tabela com os tipos de perguntas de compreensão encontrados em livros didáticos de Língua Portuguesa nos anos 1980-1990, tais como: perguntas tipo cópias, objetivas, inferenciais, globais, subjetivas e metalinguística. 
e os conhecimentos dos estudantes corroboram em uma composição particular do campo de atuação deste estudo.

Contudo, as considerações sobre as dificuldades na compreensão servem para levantar subsídios que podem remeter a níveis de discussões comuns a todos que estejam direta ou indiretamente relacionados com o processo de ensino-aprendizagem de língua estrangeira. Assim, a observação e a análise dos dados obtidos através desses sujeitos servirão como um estímulo para uma discussão mais ampla dos propósitos e caminhos adequados ao trabalho com o processo de compreensão leitora em espanhol como língua estrangeira.

Como já foi mencionado, o objetivo da pesquisa é analisar a compreensão de textos em espanhol como língua estrangeira, levando-se em consideração, o baixo rendimento dos sujeitos participantes.

Nessa perspectiva, serão apresentadas as análises das oficinas de leitura tomando como referências as atividades de compreensão aplicadas e o desempenho dos leitores na sua resolução. Para tanto, as respostas dadas às perguntas das atividades serão avaliadas segundo os níveis de compreensão que compõem a taxonomia de Barret. Por fim, com os dados obtidos nas análises de cada oficina, será feita uma comparação dos níveis de dificuldades entre os gêneros utilizados.

Análise dos dados obtidos na "Oficina A" com Histórias em Quadrinhos (HQs)

A atuação diante das HQs para uma compreensão literal de sua mensagem foi, em grande parte, efetiva na medida em que os leitores demonstraram tal compreensão ao reconhecer sequências e traços dos personagens, mas, ao mesmo tempo, dificuldades para reconhecer relações de causa e efeito, e detalhes, principalmente quando se exigia um diálogo entre os elementos verbais e não verbais tão característicos do gênero em foco.

A ação de inferir a partir dos contextos apresentados dentro das HQs foi efetivada em grande parte de forma satisfatória, principalmente para inferir 
ideias principais. No entanto, apresentaram dificuldades em inferências de causa e efeito quando exigidos para conjeturar sobre possíveis motivações dos personagens e suas interações, através de relações entre dados apresentados na sequência dos quadros com os elementos verbais e não verbais e hipóteses geradas a partir do dito além do visível.

Por fim, a partir das análises dos dados obtidos através das respostas dos leitores à atividade da "Oficina A", conclui-se que as HQs constituem exemplos de interação entre fontes diferentes de informação na compreensão textual e que a noção de texto deve ser ampliada. Em grande parte, o aspecto verbal pode ser influenciado pelo não verbal e vice-versa, como foi possível perceber nas análises que alguns leitores apresentaram dificuldade na compreensão por não conseguirem relacionar o verbal com o não verbal. Isso significa que a imagem (elemento não verbal) não é mera ilustração do texto, mas complementa e até mesmo guia a construção da coerência textual. Nesse gênero, muitas vezes, a parte verbal não pode ser compreendida sem a leitura da não verbal e, outras vezes, é constituída apenas por uma vertente não verbal.

Análise dos dados obtidos na "Oficina B" com Contos

A segunda oficina aplicada utilizou o gênero "Contos" como instrumento de verificação da compreensão textual. Nos contos, diferentemente do que ocorre nas HQs trabalhadas na oficina anterior, há a predominância do texto verbal e caracteriza-se como uma narrativa curta, envolvendo poucos personagens, onde o enredo gira em torno de apenas um conflito que se resolve em pouco tempo.

Os dois contos da oficina são autênticos e optou-se por utilizar um que, hipoteticamente, fosse de conhecimento do grupo leitor (Los tres cerditos / Os três porquinhos) e outro desconhecido (EI mundo, do uruguaio Eduardo Galeano), pois se objetivava analisar tanto o Reconhecimento como a 
Desafios na compreensão de textos em espanhol como língua estrangeira:

saberes e reflexões

Lembrança de elementos dos dois textos. Para tanto, a atividade foi aplicada em dois momentos para cada texto: um com consulta para as questões de Reconhecimento e outro sem consulta para as questões de Lembrança, Reorganização e Inferências.

Nas questões de Compreensão Literal sobre o texto I, Los tres cerditos, constatou-se que o desempenho dos leitores foi satisfatório, visto que em todas elas o número de acertos foi maior do que o de erros e o de respostas parciais. Outro aspecto relevante é o fato de que o texto em foco já era de conhecimento de 28 (vinte e oito) dos participantes, ou seja, possuíam o conhecimento prévio, o que facilitou os reconhecimentos e lembranças acerca do conto.

Já nas questões de Compreensão Inferencial, o ato de inferir a partir de um texto já conhecido na língua materna não gerou tantas dificuldades ao grupo de leitores, apesar dos erros encontrados. O conhecimento prévio de muitos estudantes pôde ser ativado e colaborou na resolução das questões.

Na questão de Reorganização, os alunos deveriam escrever um Resumo, ou seja, "uma condensação do texto mediante orações que reproduzem os fatos ou elementos mediante representações ou disposições gráficas" (ALLIENDE; CONDEMARÍN, 2005, p. 133). Após leitura de todos os textos, verificou-se que apenas 04 (quatro) conseguiram reproduzir o conto de forma mais completa e detalhada. Para ilustrar esse grupo de alunos, transcreve-se a seguir um desses resumos:

Havia três porquinhos que viviam no meio do bosque e um lobo malvado que vivia a caçar esses porquinhos, preocupados com essa situação, os porquinhos resolveram fazer umas casas para que pudessem se proteger do lobo. O porquinho menor construiu sua casa de palha para que acabasse mais rápido e junto a ele o porquinho mediano construiu uma casa de madeira, o porquinho maior, por sua vez, construiu sua casinha de tijolos. O lobo foi na primeira casinha e soprou, a casa caiu e o porco menor correu para a casa do irmão mediano, o lobo repetiu sua ação e a casinha de madeira também caiu, os dois porquinhos correram para a casa do irmão mais velho, a qual o lobo não conseguiu derrubar e tentou entrar pela chaminé, acabou sendo escaldado numa panela de água quente, foi pego pela esperteza dos porquinhos. (LEITOR 30) 
Como é possível perceber, o leitor conseguiu apresentar os personagens e o contexto no qual estavam inseridos, lembrou-se de detalhes como o material das casas, a agilidade dos porquinhos menor e mediano porque queriam terminar logo para brincar, também enfatizou a sequência das ações do lobo e foi coerente com o final do conto.

Em contrapartida, 25 (vinte e cinco) estudantes resumiram parcialmente a história deixando de fora elementos importantes para a transmissão fiel da mensagem.

Como fora dito anteriormente, a "Oficina B" possuiu dois momentos, cada um com um conto diferente. A partir de agora, far-se-á um paralelo a partir das análises do segundo conto.

Verificou-se que, apesar de ser desconhecido, comparando com o texto I, muitos participantes conseguiram executar as atividades de Compreensão Literal com reconhecimento sem muitas dificuldades mesmo sem seu conhecimento prévio, utilizando somente elementos explícitos no corpo textual. No que se refere à Compreensão Inferencial, notou-se que as inferências conjeturadas a partir de um conto desconhecido geraram mais dificuldades ao grupo de leitores, se é feita uma comparação com os resultados obtidos com o texto I, visto que o número de erros se equiparou com o de acertos.

Em uma das questões de Reorganização, os alunos precisariam escrever um Resumo do conto de Eduardo Galeano com as próprias palavras e sem consulta. A intenção era fazer um comparativo no desempenho do ato de resumir um conto já conhecido e um desconhecido, mesmo havendo o contato com os dois textos minutos antes da escrita. Somente 03 (três) estudantes conseguiram reproduzir o conto de forma mais completa e detalhada. Para ilustrar esse grupo de alunos, transcreve-se a seguir um desses resumos:

Havia um homem que morava numa vila, na Colômbia, e subiu ao alto do céu. Quando voltou, falou que viu um mar de foguinhos e que um era diferente do outro, nenhum era igual, alguns eram coloridos, outros serenos, pequenos, grandes, quentes, bobos, loucos, etc. 
Desafios na compreensão de textos em espanhol como língua estrangeira: saberes e reflexões

Ninguém era igual, pois a luz ardia mais forte do que o outro. (LEITOR 07)

Como é possível notar, o leitor conseguiu apresentar o enredo de forma sequencial coerente e com elementos importantes na composição do conto, como o lugar de origem do homem, o local para onde ele tinha ido e o que ele contou ao retornar.

Em contrapartida, 18 (dezoito) estudantes resumiram parcialmente a história deixando de fora elementos importantes para a transmissão fiel da mensagem. Os outros 9 (nove) alunos escreveram resumos equivocados, fugindo do contexto do conto e esquecendo de elementos importantes. Para ilustrar o grupo de alunos que se equivocaram na elaboração dos resumos, apresenta-se o seguinte exemplo:

Um homem colombiano viajou para conhecer o mundo e descobriu muitos lugares diferentes, cada um com sua beleza. Conheceu pessoas, pessoas diferentes, mas que para ele todas tinham o mesmo sentido: todas eram 'iguais' e cada uma delas tinha luz própria, que a igualdade era de todas. (LEITOR 23)

Pelo exemplo explanado, comprova-se a incoerência com o conto lido e que houve a tentativa de usar algum elemento do texto e criar uma história em torno dela mesmo que fugindo do tema verdadeiro.

Com isso, a partir das análises dos dados obtidos através das respostas dos leitores à atividade da "Oficina B", conclui-se que os contos, apesar de constituírem uma narrativa curta, exigem um maior trabalho para sua compreensão se comparados com as HQs. Outro aspecto relevante nesse contexto, e que influencia diretamente na leitura, é se o tema abordado é, ou não, de conhecimento do leitor, além da linguagem utilizada na composição do seu enredo.

Análise dos dados obtidos na "Oficina C" com Anúncios Publicitários

A terceira oficina aplicada trabalhou com o gênero "Publicidade", gênero este caracterizado por sua intertextualidade, texto linguístico, imagens, Entretextos, Londrina, v. 19, n. 2, p. 25- 62 / 2019 
significação das cores, fontes, público-alvo e discurso. A linguagem deste gênero textual sustenta uma argumentação icônico-linguística com fins de convencimento consciente ou inconsciente do público-alvo. Desta forma, este gênero utiliza frases curtas e concisas; palavras-chaves, carregadas de significação; adjetivos; verbos; advérbios; imperativo; elipses; linguagem figurada e outros. Além destes recursos, podem ser usados também modismos, gírias, regionalismos e neologismos, de acordo com o contexto vivenciado pelo anúncio que está sendo elaborado.

Foram utilizados quatro anúncios publicitários autênticos, dois de produtos capilares da linha Sedal e dois de conscientização acerca da grande poluição do meio ambiente devido ao uso de bolsas de plástico na sociedade.

Segundo as análises feitas, nota-se que compreender literalmente os elementos que compõem anúncios publicitários, outro exemplo de gênero multimodal utilizado neste estudo, além das HQs, também exige o diálogo entre os elementos verbais e não verbais. Nesse sentido, os leitores participantes demonstraram um bom desempenho no reconhecimento de detalhes e traços de personagens, mas vale ressaltar que em alguns momentos limitam a leitura e a fazem de modo superficial e dissociado, gerando compreensões parciais.

Pelo que foi percebido através dos dados obtidos, a Compreensão Inferencial nessa terceira oficina teve uma melhor efetivação por parte dos leitores, já que em todas as questões o número de acertos foi predominante. A elaboração de hipóteses e conclusões sobre detalhes, ideia principal e relações de causa e efeito pela maioria dos leitores superou os obstáculos que podem ser encontrados em textos multimodais como são os anúncios.

Paulo Freire (1991), em "A importância do ato de ler", já implicava a percepção crítica no processo e, já que a oficina em foco foi elaborada a partir de anúncios publicitários, nada mais coerente do que analisar tal percepção nos leitores participantes. A dimensão da Leitura Crítica perpassou pelo Julgamento de valores, visto que exigia que o leitor julgasse a atitude dos anunciantes de fazer tantas promessas aos consumidores. Os leitores demonstraram sua 
criticidade e consciência da real intenção de tais anúncios. Por exemplo, o "Leitor 12" afirmou que eles "prometem só para garantir lucro para suas empresas" e o "Leitor 08" que "prometem para atrair mais compradores". No entanto, um fato merece relevância, 7 (sete) participantes disseram acreditar nas promessas feitas pelos anunciantes da linha Sedal, como o "Leitor 04" ao dizer que a intenção dos anúncios é "melhorar a aparência e a saúde do cabeld" sem fazer menção do interesse pelos fins lucrativos.

Uma das questões da atividade demandava uma Avaliação por parte dos leitores acerca das promessas difundidas pelos anúncios publicitários. De um lado, alguns pareciam conformados, como o "Leitor 02" chegou a afirmar que "de uma certa forma convencem" e o "Leitor 10" que disse ser "interessante, pois eu uso e funciona mesmo". De outro, a opinião era contrária, por exemplo, o "Leitor 03" afirmou que eles "prometem demais e quase sempre não obtemos resultados como os da propaganda" e o "Leitor 09" ao responder que são "promessas além do que o produto pode resolver".

Após todas as reflexões acerca dos resultados da "Oficina C", conclui-se que $\mathrm{o}$ fato de ser a terceira experiência que os estudantes participam trabalhando com diferentes níveis de compreensão de textos em espanhol proporcionou um melhor rendimento. Comprova-se, portanto, a importância do trabalho contínuo, gradual e plural, no que se refere aos níveis de compreensão, em busca do aprimoramento da habilidade leitora.

Análise dos dados obtidos na "Oficina D" com Poesias

O gênero "Poesia" foi o recurso utilizado na quarta oficina para analisar as dificuldades encontradas pelos leitores na compressão textual. Tal gênero cria um diálogo entre a linguagem e o imaginário, assim como um jogo sonoro, uma beleza estética e o uso de rimas ou versos livres. Devido à comum presença de metáforas e por exigir inferências para sua compreensão, muitas 
vezes o leitor que não tem sua habilidade desenvolvida sente-se limitado e até bloqueado para dar sentidos aos textos lidos e que constituem esse gênero.

Dois textos poéticos autênticos foram utilizados: Poema $X X$ do poeta chileno Pablo Neruda e Niños de Somalia da poetisa espanhola Gloria Fuertes. Em sua poesia, Neruda deixa transparecer um eu-lírico melancólico e uma tristeza quase que desesperada por causa da ausência da amada. Já o poema de Gloria Fuertes é crítico e de cunho social, marcado pelo jogo com o verbo "comer" no intuito de protestar.

De acordo com as análises sobre as cinco perguntas da "Oficina D" centradas na Compreensão Literal, constatou-se, ao comparar os dados obtidos na "Oficina $D$ " com os das anteriores, uma maior dificuldade na compreensão literal de textos poéticos. Nesse sentido, o gênero em foco influenciou no rendimento dos leitores, comprovando a necessidade de um trabalho mais aprofundado e contínuo com poesias para o desenvolvimento da compreensão.

Em uma linha paralela, dentro da mesma atividade também havia questões centradas na Compreensão Inferencial. Das questões focadas nesse nível de compreensão, o número de acertos foi maior em metade delas, constatando assim um desempenho mediano e a importância que a inferência possui na compreensão de textos poéticos, principalmente por serem marcados por uma linguagem mais subjetiva e metafórica, exigindo que o leitor faça mais conexões entre os conhecimentos envolvidos.

Outro nível de compreensão trabalhado nessa oficina foi o da Reorganização, isto é, situar a poesia de Gloria Fuertes através da Classificação em uma categoria a partir do tema tratado, nesse caso, social, pois possui cunho crítico e realista. No grupo de estudantes, 17 (dezessete) classificaram corretamente, no entanto 13 (treze) se equivocaram e, apesar da explicação sobre cada tipo de poesia, consideraram-na como lírica (5 leitores), épica (4 leitores), bucólica (2 leitores) ou amorosa (2 leitores).

Com o intuito de travar um diálogo entre o que foi apresentado no poema com a realidade dos leitores, a última questão da atividade, contemplou 
o subnível Avaliação. A ideia era que os estudantes dissessem se a realidade existente na Somália também era vista na região onde eles viviam e qual era a opinião deles sobre isso. "Sim" foi a resposta dada por 17 (dezessete) alunos que afirmaram como o "Leitor 04" que "a fome sempre irá assolar a vida de muita gente e será problema". "Não" foi a opinião de 10 (dez) estudantes, o "Leitor 28", por exemplo, apesar de dizer que a problemática da Somália não fosse algo também presente na região onde ele vive, afirmou que "existem muitas crianças passando fome e deveriam olhar mais para esse lado e ajudar mais essas pessoas que tanto precisam". A resposta de 2 (dois) leitores foi intrigante pois associaram a poesia Niños de Somalia e as imagens trabalhadas com o racismo, tema não indicado nas reflexões.

Nessa perspectiva, os resultados das análises da "Oficina D" comprovam a necessidade da inserção do texto poético dentro das aulas de espanhol como língua estrangeira contemplando diferentes níveis de compreensão, mas também ampliando a visão de mundo dos leitores sobre a cultura hispânica e apresentando diferentes temáticas na composição dos conteúdos dos poemas.

\section{Análise dos dados obtidos na "Oficina E" com Notícias}

A última oficina de análise das dificuldades para compreender textos em espanhol como língua estrangeira fez uso do gênero "Notícia". A escolha desse gênero específico para finalizar o processo de aplicação de oficinas deve-se a grade importância desse tipo de leitura para a formação do leitor, para que o mesmo seja hábil em entender, integrar-se e atuar na realidade social em que está inserido, através da formação de opiniões e do desenvolvimento da capacidade de reflexão e criticidade, essencial para assegurar sua participação como cidadão do mundo.

As duas notícias utilizadas na oficina também são exemplos de textos autênticos e, como foi feito na "Oficina B" com "Contos", optou-se por utilizar 
uma notícia de um fato divulgado também no Brasil e com grande repercussão, e uma de um acontecimento talvez desconhecido pelo grupo de participantes.

A intenção do uso de duas notícias com temas e repercussões distintas era analisar tanto o Reconhecimento como a Lembrança de elementos dos dois textos. Por isso, a atividade foi aplicada em dois momentos para cada texto: um com consulta para as questões de Reconhecimento e outro sem consulta para as questões de Lembrança, Reorganização e Inferências.

A atividade sugerida possuía 20 (vinte) perguntas, 10 (dez) sobre a primeira notícia, Fallece el cómico mexicano Roberto Gómez Bolaños, e 10 (dez) sobre a segunda, Uma niña de 12 años y um niño de 13 años se convierten en los padres más jóvenes de Reino Unido.

Como foi visto nas questões de Compreensão Literal sobre a notícia I, Fallece el cómico mexicano Roberto Gómez Bolaños, constatou-se que o desempenho dos leitores foi satisfatório, visto que em somente uma delas o número de acertos foi menor do que o de erros. Outro aspecto relevante é o fato de que o acontecimento noticiado já era de ciência de todos os participantes, sendo assim, o conhecimento prévio contribuiu nos processos de reconhecimentos e lembranças acerca da notícia.

Além dos aspectos analisados anteriormente, outro nível de compreensão foi contemplado as questões sobre o texto I da "Oficina $E^{\prime}$, a Compreensão Inferencial, pela análise feita, comprovou-se que o ato de inferir tomando como referencial algo já conhecido não gerou tantas dificuldades ao grupo de leitores, apesar dos erros encontrados. O conhecimento prévio de muitos estudantes pôde ser ativado e colaborou na resolução das questões, assim como aconteceu na "Oficina B" com o conto Los tres cerditos.

Na questão de Reorganização, os alunos deveriam escrever um Resumo da notícia lida utilizando suas próprias palavras e incluindo uma manchete. Após leitura de todos os textos, verificou-se que nenhum deles conseguiu reproduzir a notícia de forma completa e detalhada. No entanto, 27 (vinte e 
sete) mostraram capacidade de reorganizar as ideias do texto lido de modo parcial, recordando de algumas informações e esquecendo-se de outras.

Ao comparar alguns resumos, que representam o grupo de respostas parciais, percebe-se que conseguiram lembrar-se de muitos elementos da notícia e que outros foram bastante sucintos. A manchete criada pela maioria na reescrita segue o padrão do texto original centrado na divulgação da morte de Roberto Bolaños. Na composição do texto, houve a citação da data, local e motivo da morte, além da idade com a qual veio a falecer. Outras informações recorrentes nos resumos faziam menção às esposas, filhos e personagens do ator e dramaturgo.

Nessa perspectiva, mesmo com poucos erros de reorganização das ideias para elaboração do resumo, o grupo de participantes teve um bom desempenho, visto que contemplaram muitos elementos do texto original e fizeram uso do conhecimento prévio do fato na execução da atividade.

Como fora dito anteriormente, a "Oficina E" também foi estruturada para ocorrer em dois momentos, cada um com uma notícia diferente. A partir de agora, far-se-á um paralelo através das análises da segunda notícia.

Na pesquisa, contatou-se que nas perguntas de Compreensão Literal da "Oficina $E^{\prime \prime}$ o desempenho dos leitores foi satisfatório. Vale ressaltar que, apesar da notícia mencionar um fato desconhecido, comparando com o texto I, muitos participantes mostraram interesse e espanto com o caso noticiado e conseguiram executar as atividades de reconhecimento sem muitas dificuldades, mesmo sem o conhecimento prévio, utilizando o reconhecimento e a lembrança de elementos explícitos no corpo textual.

A partir das análises das quatro de Compreensão Inferencial, notou-se que as inferências conjeturadas a partir da notícia de um fato desconhecido não geraram tantas dificuldades ao grupo de leitores, visto que seu conteúdo suscitou interesse no caso e que o número de erros só foi maior que o de acertos em uma das questões. 
Desafios na compreensão de textos em espanhol como língua estrangeira: saberes e reflexões

A questão de dimensão da Leitura Crítica demandou o Julgamento de valores, visto que exigia que o leitor expressasse sua opinião sobre a problemática da notícia. Os leitores demonstraram sua criticidade e posicionamento sobre o caso inglês.

O quarto e último nível de compreensão trabalhado com o texto II da "Oficina E" foi o de Reorganização presente na última questão, na qual os alunos precisariam escrever um Resumo do caso noticiado no texto II com as próprias palavras e sem consulta. Do grupo de participantes, 26 (vinte e seis) resumiram parcialmente a história deixando de fora elementos importantes para a transmissão fiel da mensagem.

Apenas 3 (três) estudantes não conseguiram reproduzir a notícia de forma correta, tais erros foram identificados por fugirem do contexto da notícia e podem ser explicados pelo esquecimento de elementos importantes, visto que tinham conhecido o enredo minutos antes de sua escrita e, nesse momento, não poderiam consultá-lo. Para ilustrar esse grupo de alunos, transcrevem-se a seguir dois desses resumos:

MÃES NA ADOLESCÊNCIA E CASAL DE PADRES MAIS JOVENS DO REINO UNIDO

Em uma cidade do Reino Unido vivia ou vive um casal de padres que se consagraram muito jovens.

Na mesma cidade existe uma mãe que deu a luz a seu filho em 2006 aos 13 anos e 8 meses, mas pensaram que ela seria a mãe mais jovem do mundo, depois descobriram que existia outra que morava no Peru e que teve seu filho aos cinco anos de idade em 1939.

Moral: se previna por você pode ser uma dessas jovens que são mães muito jovens. Faça tudo com prevenção. (LEITOR 07)

\section{A RELAÇÃO PREMATURA}

Duas crianças resolveram se casar no país de Londres onde ficaram conhecidos como o casal mais jovem a receber a benção do padre. Atualmente, isso não é nenhuma novidade, jovens estão tendo relações antes da idade certa, ou seja, prematuramente. A maioria desses jovens estão engravidando muito cedo, sendo que não estão preparados psicologicamente, financeiramente para a chegada dessa criatura. Muitas vezes eles não têm o apoio da sua própria família, ou seja, tem que criar seus filhos sozinhos. E isso é uma realidade muito frequente não só aqui no Brasil, como também em outros países. São jovens que sem receber uma boa educação sexual perdem sua 
Desafios na compreensão de textos em espanhol como língua estrangeira: saberes e reflexões

juventude pra cuidar de um bebê, ou seja, um bebê cuidando do outros. (LEITOR 12)

Pelos exemplos explanados, constatam-se incoerências com o texto lido e que houve a criação de um novo com alguns elementos da notícia autêntica, mas fugindo do tema verdadeiro. 0 "Leitor 07 " aponta que a notícia é sobre "um casal de padres que se consagraram muito jovens", equívoco cometido pelo não entendimento do heterosemântico "padre" que em espanhol significa "pai" e não "sacerdote" e "convertirse" associando com conversão religiosa, relaciona os casos das três crianças de modo errôneo e inclui uma moral para a história, elemento não constitutivo do gênero notícia. Por fim, o "Leitor 12" afirma em seu resumo que as duas crianças ficaram conhecidas como o casal mais jovem a se casar e receber a benção do padre, mesmo erro com o falso cognato do "Leitor 07 ", vale ressaltar a expressão da própria opinião no corpo do texto sobre $o$ assunto e comparação com o Brasil, recursos não presentes na notícia.

Sendo assim, e segundo as análises dos dados obtidos através das

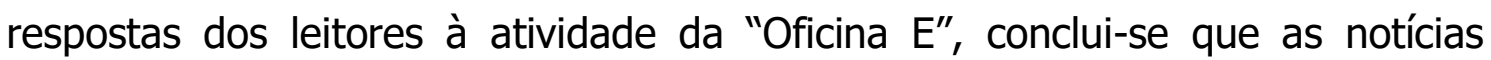
utilizadas, gênero textual do cotidiano em diferentes suportes, seus temas e linguagem contribuíram para que o número de acertos fosse maior do que o de erros, e para que estes constituíssem a fundamentação para a análise das dificuldades de compreensão.

\section{Análise Comparativa entre os Gêneros}

Como estratégia conclusiva, será apresentada uma visão global dos resultados obtidos por meio de algumas considerações constatadas durante as análises. Para tanto, os aspectos referentes a cada categoria estipulada levarão em consideração o trabalho com os diferentes gêneros discursivos de modo comparativo objetivando sintetizar os resultados obtidos nas análises das atividades das oficinas de leitura. 
Desafios na compreensão de textos em espanhol como língua estrangeira: saberes e reflexões

Apresenta-se, no quadro a seguir, o número de questões que geraram mais dificuldades para cada leitor a partir da soma das questões com maior número de respostas erradas e parciais. Como o número total de questões foi diferente entre as oficinas, torna-se imprescindível calcular a porcentagem proporcional ao número total de questões para que assim seja possível fazer uma análise comparativa dos dados. 
Desafios na compreensão de textos em espanhol como língua estrangeira:

saberes e reflexões

Quadro 2 - Número de questões por gênero que geraram dificuldades aos leitores na compreensão

\begin{tabular}{|l|l|l|l|}
\hline Oficinas & $\begin{array}{l}\text { Número total de } \\
\text { questões }\end{array}$ & $\begin{array}{l}\text { Número de questões que } \\
\text { geraram dificuldades }\end{array}$ & Percentual \\
\hline HQs & 10 & 04 & $40 \%$ \\
\hline Conto I & 13 & 01 & $7,69 \%$ \\
\hline Conto II & 11 & 04 & $36,3 \%$ \\
\hline Anúncios & 15 & 03 & $20 \%$ \\
\hline Poesias & 15 & 07 & $46,6 \%$ \\
\hline Notícia I & 10 & 02 & $20 \%$ \\
\hline Notícia II & 10 & 03 & $30 \%$ \\
\hline
\end{tabular}

Fonte: Autor

Com os dados do quadro acima, é possível verificar o grau de dificuldade de cada gênero a partir do percentual de questões que resultaram no maior número de erros e de respostas parciais. Visto isso, ao colocar esses resultados em ordem decrescente, tem-se a seguinte lista classificatória do gênero que gerou mais dificuldades ao que teve resultados menos negativos.

Quadro 3 - Lista classificatória dos gêneros discursivos por grau de dificuldades

\begin{tabular}{|l|l|l|}
\hline $\mathbf{1 0}^{\mathbf{0}}$ & Poesias & $46,6 \%$ \\
\hline $\mathbf{2 0}^{\circ}$ & Histórias em Quadrinhos & $40 \%$ \\
\hline $\mathbf{3}^{\circ}$ & Conto II - El mundo (Eduardo Galeano) & $36,3 \%$ \\
\hline $4^{\circ}$ & Notícia II - Los padres más jóvenes de Reino Unido & $30 \%$ \\
\hline $\mathbf{5}^{\circ}$ & Anúncios & $20 \%$ \\
\hline $6^{\circ}$ & Notícia I - Muerte de Roberto Gómez Bolaños & $20 \%$ \\
\hline $7^{\circ}$ & Conto I - Los tres cerditos & $7,69 \%$ \\
\hline
\end{tabular}

Fonte: Autor

A disposição dos gêneros no quadro acima indica que a oficina com "Poesias" foi a que gerou mais dificuldades, pois teve o maior índice de erros e de respostas parciais. A compreensão de textos poéticos exigiu um maior domínio de inferências por sua linguagem ser marcada, muitas vezes, pela linguagem rebuscada, pela subjetividade e pelo uso de metáforas, exigindo que, como fora dito, o leitor faça mais conexões entre os conhecimentos envolvidos. 
Desafios na compreensão de textos em espanhol como língua estrangeira: saberes e reflexões

O gênero "HQs" assumiu o segundo lugar na lista dos gêneros discursivos por grau de dificuldades. Gênero multimodal que exigiu o diálogo entre elementos verbais e não verbais. Mesmo com sua composição de textos verbais curtos, resultaram mais complexos que os textos narrativos. Outro dado importante é que essa foi a primeira oficina a ser aplicada com todos os estudantes e, por ser o primeiro contato com a proposta, a inexperiência influenciou diretamente nos resultados.

O conto II "El mundo", de Eduardo Galeano, da "Oficina B" foi o terceiro colocado na lista de gêneros mais dificultosos e, durante a aplicação da atividade, muitos alegaram achar mais complexo que o primeiro conto, indicando que a problemática não foi causada pelo gênero em foco, mas sim por seu conteúdo, já que os leitores não tinham conhecimento prévio da temática, com isso questiona-se até que ponto o gênero e a temática do texto influenciam na sua compreensão.

A quarta colocação ficou com a notícia II que retratou o caso dos pais mais jovens do Reino Unido. A polêmica do fato incitou a curiosidade dos leitores e permitiu uma conexão com casos recorrentes na atualidade e no contexto dos participantes. $O$ texto jornalístico de caráter informativo apresenta uma linguagem formal e objetiva, e pode ser veiculado em diferentes suportes, tais aspectos não foram obstáculos mesmo tratando-se de um gênero ilustrado em espanhol, pois toda experiência prévia na língua materna contribuiu para o processo leitor.

Os anúncios da "Oficina C", outro exemplo de gênero multimodal que associou elementos verbais e não verbais, ocupou a quinta colocação. Sua posição quase no final da lista, diferentemente do segundo lugar das HQs, demonstraria outra controvérsia se houvesse uma generalização dos gêneros por sua multimodalidade. A informalidade e familiaridade do texto publicitário possibilitaram uma melhor interação com o leitor, apesar de muitos destes demonstrarem limitações ao relacionar os elementos verbais e não verbais. 
A penúltima colocação ficou com a notícia I que anunciou a morte do mexicano Roberto Bolaños. A ativação do conhecimento prévio, por contemplar uma temática já conhecida e que faz parte do conhecimento de mundo dos leitores, influenciou diretamente nesse resultado, apesar da composição desse gênero ser predominantemente verbal, o que hipoteticamente poderia dificultar a compreensão.

A atividade sobre o "Conto" Los tres cerditos, provavelmente por ser um texto já conhecido na língua materna do grupo de leitores participantes, obteve os melhores resultados. Nesse sentido, tanto as questões de reconhecimento como as de lembrança, de compreensão inferencial, reorganização e avaliação, tiveram melhores resultados com esse conto por já ser conhecido. A única questão que apresentou maior número de respostas parciais foi a que demandava a elaboração do resumo do conto, fato compreensível visto que a maioria recordou elementos importantíssimos da história, dos personagens e das sequências, porém torna-se quase impossível lembrar, sem exceção, de todos os detalhes presentes no enredo.

\section{Considerações Finais}

Para finalizar as discussões travadas no presente trabalho, torna-se imprescindível retomar alguns dos pontos mais importantes na composição do estudo desenvolvido. $\mathrm{O}$ objetivo geral da presente pesquisa foi analisar a compreensão de textos em espanhol como língua estrangeira com alunos que, hipoteticamente, apresentam dificuldades na habilidade leitora, visto que possuem um baixo rendimento escolar mesmo apresentando um bom comportamento, esforço e dedicação à disciplina. Nesse sentido, as reflexões aqui realizadas poderão contribuir para o fomento de novos estudos e para 0 aprimoramento da prática docente no que concerne ao trabalho com a compreensão de textos em espanhol como língua estrangeira e as dificuldades que a permeiam. 
Desafios na compreensão de textos em espanhol como língua estrangeira: saberes e reflexões

Sendo assim, a análise comparativa das dificuldades com os gêneros discursivos utilizados identificou que tanto a temática tratada no texto, como o gênero e a linguagem empregada influenciam no processo leitor. Sobre os temas dos textos, comprovou-se que os conhecimentos prévios são ativados e utilizados na atividade leitora em prol de uma compreensão efetiva. Em contrapartida, tal aspecto provocou alguns questionamentos acerca da limitada compreensão de alguns estudantes que, por fazerem parte do Ensino Médio, hipoteticamente, deveriam ser capazes de compreender temas que estão além do seu contexto e vivências. No que concerne à linguagem empregada nos textos, verificou-se que o vocabulário foi um dos obstáculos encontrados pelos leitores, problemática justificável quando se fala de estudantes que iniciaram seus estudos do espanhol no Ensino Médio (apenas meses, um ou dois anos), pouco tempo para uma rica aquisição de vocabulário. Além disso, a questão sintática também pode ser um fator influenciador, visto que há diferenças em sua construção, ao comparar com a língua materna dos estudantes, apontando para a necessidade do trabalho de aquisição do idioma de forma contextualizada, a partir de situações autênticas de uso, algo que ratifica o papel do texto como recurso essencial no ensino-aprendizagem de espanhol como língua estrangeira. Por fim, no que se refere à influência dos gêneros, contatou-se que a materialização dos textos através dos diversos gêneros também demanda um conhecimento que deve ser trabalhado e ampliado no contexto escolar e, ao mesmo tempo, reconhecido fora dele, nas práticas comunicativas do cotidiano em língua materna, principalmente tratando-se de uma língua estrangeira, pois contribuirá para que o leitor possa trafegar em diferentes contextos comunicativos.

Com todas as reflexões que compuseram esta investigação, espera-se que ela possa contribuir para os estudos da compreensão leitora, principalmente associada ao espanhol como língua estrangeira, campo ainda carente de pesquisa nessa área. Pensar nas dificuldades que os leitores possuem ao interagirem com textos em espanhol é abrir caminhos para 
possíveis resoluções que possam ajudá-los a superar os obstáculos e os limites impostos por tais problemas. Ao compreender como funciona o processo leitor e os distintos níveis de compreensão que envolvem essa interação comunicativa, estudantes, professores, pesquisadores, enfim, leitores que percorram os caminhos traçados neste trabalho poderão aprofundar e ampliar sua visão sobre o tema, além de abrir portas para novos estudos e práticas que corroborem no auxilio da redução e mediação das dificuldades na compreensão de textos em espanhol como língua estrangeira, assim como no aprofundamento de questões voltadas para o ensino da língua espanhola a alunos com diferentes dificuldades de leitura.

\section{Referências}

ALLIENDE, Felipe; CONDEMARÍN, Mabel. A leitura, teoria, avaliação $e$ desenvo/vimento. Tradução de Ernani Rosa. Porto Alegre: Artmed, 2005.

BAKHTIN, Mikail. Estética da criação verbal. 2. ed. São Paulo: Martins Fontes, 1997.

BRASIL. Ministério da Educação. Orientações curriculares para o ensino médio (OCEM): linguagens, códigos e suas tecnologias. Brasília: Ministério da Educação, Secretaria de Educação Média e Tecnológica, 2006. v.1.

BRASIL. Ministério da Educação. Parâmetros curriculares nacionais do ensino médio: linguagens, códigos e suas tecnologias. Brasília: Secretaria de Educação Média e Tecnológica, 2000.

DIONISIO, Ângela Paiva. Gêneros textuais e multimodalidade. In: KARWOSKI, Acir Mário; GAYDECZKA, Beatriz; BRITO, Karim Siebeneicher (org.). Gêneros textuais. reflexões e ensino. São Paulo: Parábola Editorial, 2011.

FONTANA, B. Material autêntico e educação em língua estrangeira. Entrelinhas (UEL), São Leopoldo, RS, p. 10-13, 2003. Disponível em:http://cienciaparaeducacao.org/eng/publicacao/fontana-b-materialautentico-e-educacao-em-lingua-estrangeira-entrelinhas-uel-sao-leopoldo-rs-p10-13-2003/. Acesso em: 9 out. 2014.

FREIRE, Paulo. $A$ importância do ato de ler. em três artigos que se completam. São Paulo: Cortez Editora \& Autores Associados, 1991. (Coleção Polêmicas do Nosso Tempo, v. 4). 
Desafios na compreensão de textos em espanhol como língua estrangeira: saberes e reflexões

GIL, Antônio Carlos. Como elaborar projetos de pesquisa. 5. ed. São Paulo: Atlas, 2010.

GODOY, Arilda Schmidt. Introdução à pesquisa qualitativa e suas possibilidades. Revista de Administração de Empresas, São Paulo, v. 35, n. 2, p. 57-63, abr. 1995.

INEP - Instituto Nacional de Estudos e Pesquisas Educacionais Anísio Teixeira. Guia de elaboração e revisão de itens. Brasília: INEP, 2010. v. 1

KLEIMAN, Ângela. O estatuto interdisciplinar da linguística aplicada: o traçado de um percurso, um rumo para o debate. In: SIGNORNI, Inês; CAVALCANTE, Marilda do Couto (org.). Linguística aplicada e transdisciplinaridade. Campinas, SP: Mercado de Letras, 1998. p. 51-77.

KLEIMAN, Ângela. Oficinas de leitura: teoria e prática. São Paulo: Pontes, 1998.

$\mathrm{KOCH}$, Ingedore Grunfeld Villaça. Desvendando os segredos do texto. 2. ed. São Paulo: Cortez, 2003.

MARCUSCHI, Luiz Antônio. Produção de texto, análise de gêneros e compreensão. São Paulo: Parábola Editorial, 2008.

MOITA LOPES, Luiz Paulo da. Oficina de linguística aplicada: a natureza social e educacional dos processos de ensino/aprendizagem de línguas. Campinas, SP: Mercado das Letras, 1996.

MOITA LOPES, Luiz Paulo da. Por uma linguística aplicada indisciplinar. São Paulo: Editora Parábola, 2006.

PAES DE BARROS, Cláudia Graziano. Capacidades de leitura de textos multimodais. Polifonia, Cuiabá, n. 19, p. 161-186, 1. sem. 2009.

PINHEIRO, Clemilton Lopes. Processos referenciais em textos multimodais. aplicação ao ensino. Anais do SIELP, Uberlândia, MG, v. 2, n. 1, 2012. Disponível em: www.ileel.ufu.br/anaisdosielp/pt/arquivos/sielp2012/562.pdf. Acesso em: 25 ago. 2014.

ROJO, Roxane Helena Rodrigues. Gêneros do discurso no círculo de Bakhtin: ferramentas para a análise transdisciplinar de enunciados em dispositivos e práticas didáticas. In: SIMPÓSIO INTERNACIONAL DE ESTUDOS E GÊNEROS TEXTUAIS, 4., 2007, Tubarão, SC. Anais [...]. Tubarão, SC: UNISUL, 2007. p. 1761-1775. CD-ROM.

SELVATICI, Vera Lucia Carvalho Grade. $A$ análise textual de um texto multimodal. Pesquisas em Discurso Pedagógico [online], Rio Janeiro, 2007. 
Desafios na compreensão de textos em espanhol como língua estrangeira: saberes e reflexões

Disponível em: http://www.maxwell.lambda.ele.puc-

rio.br/rev_discurso.php?strSecao=input0. Acesso em: 25 ago. 2014.

SOLÉ, Isabel. Estratégias de leitura. Porto alegre: Artes médicas, 1998. 